\title{
Cortisol in tissue and systemic level as a contributing factor to the development of metabolic syndrome in severely obese patients
}

\author{
Petros Constantinopoulos ${ }^{1}$, Marina Michalaki ${ }^{1}$, Anastasia Kottorou ${ }^{3}$, \\ loannis Habeos' ${ }^{1}$, Agathoklis Psyrogiannis ${ }^{1}$, Fotios Kalfarentzos ${ }^{2}$ and \\ Venetsana Kyriazopoulou' \\ ${ }^{1}$ Division of Endocrinology, Diabetes and Metabolic Diseases, Department of Internal Medicine, \\ ${ }^{2}$ Division of Nutritional Support and Morbid Obesity, Department of Surgery and ${ }^{3}$ Molecular Oncology \\ Laboratory, Medical School, University of Patras, 26500 Patras, Greece
}

\author{
Correspondence \\ should be addressed \\ to V Kyriazopoulou \\ Email \\ vkyriazopoulou@ \\ med.upatras.gr
}

\begin{abstract}
Context: Adrenal and extra-adrenal cortisol production may be involved in the development of metabolic syndrome (MetS). Objective: To investigate the activity of the hypothalamic-pituitary-adrenal (HPA) axis and the expression of HSD11B1, nuclear receptor subfamily 3, group $C$, member 1 (glucocorticoid receptors) $\alpha$ (NR3C1 $\alpha$ ) and $\beta$ (NR3C1 $\beta$ ) in the liver, subcutaneous adipose tissue (SAT) and visceral adipose tissue (VAT) of severely obese patients with and without MetS. Methods: The study included 37 severely obese patients (BMI $\geq 40 \mathrm{~kg} / \mathrm{m}^{2}$ ), 19 with MetS (MetS + group) and 18 without (MetS - group), studied before and during bariatric surgery. Before the day of surgery, urinary free cortisol (UFC) and diurnal variation of serum and salivary cortisol were estimated. During surgery, biopsies of the liver, VAT and SAT were obtained. The expression of HSD11B1, NR3C1 $\alpha$ and NR3C1 $\beta$ was evaluated by RT-PCR.

Results: UFC and area under the curve for 24-h profiles of serum and salivary cortisol were lower in the MetS - group. In the MetS - group, mRNA levels of HSD11B1 in liver exhibited a negative correlation with liver NR3C1 $\alpha$ (LNR3C1 $\alpha$ ) and VAT expression of HSD11B1 was lower than the MetS + group.

Conclusions: We observed a downregulation of the NR3C1 $\alpha$ expression and lower VAT mRNA levels of HSD11B1 in the MetS - group, indicating a lower selective tissue cortisol production and action that could protect these patients from the metabolic consequences of obesity. In the MetS - group, a lower activity of the HPA axis was also detected. Taken together, cortisol in tissue and systematic level might play a role in the development of MetS in severely obese patients.
\end{abstract}

\section{Introduction}

After Reaven (1) first described syndrome X, 26 years ago, metabolic syndrome (MetS), as it is defined nowadays, demonstrates a notable increasing prevalence, due to a worldwide epidemic of obesity and diabetes (2). Thus, justifiably, it consists, along with obesity, a major field of research and controversies. As it is well known, MetS is recognised as a major and prevalent risk factor for cardiovascular disease (CVD) by the World Health Organization (WHO) (3), the National Cholesterol Education Program-Adult Treatment Panel III
(NCEP-ATP III) (4) and the International Diabetes Federation (IDF) (5), pointing out the growing necessity to clarify its pathophysiology and subsequently to establish effective treatment.

During the last few years, the resemblance of the clinical signs, symptoms and biochemical findings between Cushing's syndrome and MetS $(6,7,8)$ has been highlighted, suggesting that cortisol may play a key role in all these entities. However, idiopathic obese patients have normal circulating levels of cortisol, indicating that (c) 2015 European Society of Endocrinology Printed in Great Britain
Published by Bioscientifica Ltd. 
research needs to focus on the tissue level and the intracellular metabolism of glucocorticoids.

It is well known that the intracellular glucocorticoid metabolism is regulated at a pre-receptor level by the activity of two isoforms of the $11 \beta$-hydroxysteroid dehydrogenase enzyme: Hydroxysteroid (11-beta) dehydrogenase 1 and 2 (HSD11B1 and HSD11B2). The enzyme HSD11B1 promotes the extra-adrenal production of cortisol by catalysing the regeneration from inactive cortisone and thus amplifying glucocorticoid action at the pre-receptor level. HSD11B1 is widely expressed throughout the body, mainly in the liver as well as in other tissues such as the visceral adipose tissue (VAT) and subcutaneous adipose tissue (SAT) $(9,10,11,12,13)$.

The pathogenic role of HSD11B1 in the development of visceral obesity and key features of MetS has been demonstrated in transgenic mice models. In these studies, mice with selective overexpression of HSD11B1 in adipose tissue had increased adipose levels of corticosterone and therefore developed visceral obesity, also exhibiting pronounced insulin-resistant diabetes and hyperlipidaemia (14). Furthermore, in another study, transgenic mice, which were expressing increased HSD11B1 activity selectively in the liver, developed MetS without obesity, which was associated with fatty liver, dyslipidaemia, mild insulin resistance (IR) and increased angiotensinogen expression (15). In the opposite, Hsd11b1-knockout mice did not develop IR or glucose intolerance on hypercaloric diets. They demonstrated an improved lipid and lipoprotein profile, hepatic insulin sensitivity and glucose tolerance, and they resisted hyperglycaemia on obesity or stress $(16,17,18)$.

Fat depots can be distinguished, based on their anatomical distribution as VAT (omental and mesenteric) and SAT. Visceral fat is considered to have a stronger association with the different features of MetS $(19,20,21,22)$.

Obese patients do not always have MetS, thus constituting an intriguing metabolically 'healthy' obese phenotype, which is linked with a lower risk of all-cause mortality and CVD compared with obese subjects with MetS $(23,24)$. Therefore, questions arise about the factors that contribute to the appearance of the metabolic features of MetS in obese patients. Moreover, data regarding the expression of HSD11B1 in adipose tissue of obese patients remains conflicting.

The aim of this study was to evaluate the activity of the hypothalamic-pituitary-adrenal (HPA) axis and the expression of HSD11B1 and nuclear receptor subfamily 3, group C, member 1 (glucocorticoid receptors) $\alpha$ (NR3C1 $\alpha$ ) and $\beta(\mathrm{NR} 3 \mathrm{C} 1 \beta)$ in SAT, VAT and the liver of severely obese patients with or without MetS, and to investigate the possible associations and discrepancies relating to MetS.

\section{Patients and methods}

\section{Patients}

Before bariatric surgery, 37 severely obese patients (BMI $\geq 40 \mathrm{~kg} / \mathrm{m}^{2}$ ) were recruited prospectively in the University Hospital of Patras (Greece) and were enrolled in the study. All participants underwent a complete clinical (including anthropometric measurements), biochemical and endocrine assessment before surgery, which included an oral glucose tolerance test with $75 \mathrm{~g}$ of glucose and measurement of the fasting insulin and C-peptide, baseline adrenocorticotrophin (ACTH), thyrotrophin (TSH), tri-iodothyronine $\left(\mathrm{T}_{3}\right)$, thyroxine $\left(\mathrm{T}_{4}\right)$ and urinary free cortisol (UFC) (24-h urine collection). Moreover, serum and salivary cortisol levels were measured at scheduled times $(0800 \mathrm{~h}, 1400 \mathrm{~h}, 1800 \mathrm{~h}$, and $2300 \mathrm{~h})$.

The patients were divided into two groups, MetSand MetS +, according to the presence of MetS as defined by the IDF criteria (5). The MetS - group consisted of 18 patients (mean age $34.7 \pm 8.3$ years, BMI $53.7 \pm 7.7 \mathrm{~kg} / \mathrm{m}^{2}$, five (28\%) males, 13 (72\%) females), whereas the MetS+ group consisted of 19 patients (mean age $44.1 \pm 9.6$ years, BMI $52.4 \pm 5.8 \mathrm{~kg} / \mathrm{m}^{2}$, nine males $(47 \%)$, ten females $(53 \%))$. All patients underwent bariatric surgery. None of these patients received any medication known to interfere with the regulation of HSD11B1 or the HPA axis.

IR was evaluated by the homeostatic model assessment (HOMA) using the following equation: fasting insulin $(\mu \mathrm{IU} / \mathrm{ml}) \times$ fasting plasma glucose $(\mathrm{mg} / \mathrm{dl}) / 405$. Insulin sensitivity was also assessed by the quantitative insulin sensitivity check index (QUICKI) using the formula: 1/(log (fasting insulin $\mu \mathrm{U} / \mathrm{ml}$ ) $+\log$ (fasting glucose $\mathrm{mg} / \mathrm{dl}$ )).

Body composition was estimated by bioelectrical impendence (BC-418 Segmental Body Composition Analyzer; Tanita Europe B.V., Amsterdam, The Netherlands).

A signed consent was obtained from all patients and the protocol was approved by the Ethical Committee of the University Hospital of Patras (Greece).

\section{Biochemical measurements/hormone assays}

Glucose, urea, creatinine, electrolytes, cholesterol, triglycerides (TG), and liver chemistry, which included serum transaminases (alanine aminotransferase, aspartate aminotransferase), serum alkaline phosphatase, $\gamma$-glutamyl 
transpeptidase, bilirubin and albumin, were measured by an enzymatic colorimetric assay using an automated clinical chemistry analyser. Serum, salivary and urinary cortisol, ACTH, TSH, $\mathrm{T}_{3}, \mathrm{~T}_{4}$, insulin and C-peptide levels were measured by chemiluminescence immunoassays (Modular Analytics E170; Roche Diagnostics). More specifically for urinary cortisol, $600 \mu \mathrm{l}$ of urine and $3.0 \mathrm{ml}$ of dichloromethane were mixed in a glass tube for $7 \mathrm{~min}$. Then it was centrifuged for $5 \mathrm{~min}$ at $2500 \boldsymbol{g}$ to separate the phases. The aqueous phase and possible residues at the phase interface were removed and discarded. The dichloromethane phase $(1.5 \mathrm{ml})$ was transferred into a clean glass tube and, under a hood; it was reduced until dry by exposing it to a gentle nitrogen flow. The dry residue was reconstituted with $300 \mu \mathrm{l}$ of diluent universal and incubated for $30 \mathrm{~min}$ at $15-25^{\circ} \mathrm{C}$ while occasionally mixing it four times for $1 \mathrm{~min}$ in a rotating shaker. Finally, the reconstituted sample was analysed by chemiluminescence immunoassays (Modular Analytics E170; Roche Diagnostics). Saliva was collected into a commercially available device, a Salivette (Sarstedt, Numbrecht, Germany), using a cotton swab chewed on for 2-3 min, which was then inserted into a double-chamber plastic test tube. The intra-assay co-efficient of variation was 1.9-2\% for insulin, $1.3-4.6 \%$ for C-peptide, $2-2.9 \%$ for ACTH, $1.8-8.6 \%$ for $\mathrm{TSH}, 2.5-4.7 \%$ for $\mathrm{T}_{4}$ and $3.6-5.3 \%$ for $\mathrm{T}_{3}$. Moreover, the intra-assay co-efficient of variation was $1.1-1.3 \%$ for serum cortisol, $1.5-6.1 \%$ for salivary cortisol and $2.2-2.9 \%$ for urinary cortisol. The inter-assay coefficient of variation was $2.5-2.8 \%$ for insulin, $1.8-5 \%$ for C-peptide, 2.4-5.4\% for ACTH, 3.3-8.7\% for TSH, 3-6.9\% for $\mathrm{T}_{4}, 4.7-5.4 \%$ for $\mathrm{T}_{3}, 1.5-1.6 \%$ for serum cortisol, $4.1-33.4 \%$ for salivary cortisol and $1.8-3.2 \%$ for urinary cortisol.

\section{Fat and liver biopsies}

During surgery, biopsies of the VATs and SATs as well as the liver biopsies were obtained from all patients during the first 30-60 min after the skin incision. The samples were immediately placed in sample containers containing RNAlater RNA Stabilisation Reagent (Qiagen) and stored at $-80{ }^{\circ} \mathrm{C}$ until further analysis.

\section{RNA extraction and RT}

Total RNA was extracted from $100 \mathrm{mg}$ of VAT and $100 \mathrm{mg}$ of SAT (RNeasy Lipid Tissue kit; Qiagen). Total RNA was also extracted from $100 \mathrm{mg}$ of liver (RNeasy mini kit; Qiagen). The samples were incubated with DNAase (Ambion, Austin, TX, USA) and then quantified using a Nanodrop-1000 spectrophotometer (NanoDrop,
Fisher Thermo, Wilmington, DE, USA) and an MX3000p real-time (RT) PCR system (Stratagene, La Jolla, CA, USA) according to the instructions of the manufacturers. The RNA was checked by electrophoresis on $1 \%(\mathrm{w} / \mathrm{v})$ agarose gels and then it was stored at $-80^{\circ} \mathrm{C}$. A total of $1.8 \mu \mathrm{g}$ of RNA was reverse transcribed into cDNA using $100 \mathrm{u}$ of Superscript III Reverse Transcriptase (Life Technologies), $300 \mathrm{ng}$ of random primers (Foundation for Research and Technology-Hellas, Crete, Greece) and $5 \mathrm{nM}$ dNTPs (Stratagene) in a final volume of $50 \mu \mathrm{l}$. A no enzyme control was used to ensure that the RNA was DNA-free. cDNA was stored at $-20^{\circ} \mathrm{C}$ until PCR was performed.

\section{PCR for HSD11B1 and NR3C1 $\alpha / \beta$}

The levels of expression of HSD11B1, NR3C1 $\alpha, \mathrm{NR} 3 \mathrm{C} 1 \beta$ and TATA box-binding protein (TBP) were quantified using the intercalating dye SYBR Green I in a Kapa Sybr Fast MasterMix (KAPA Biosystems, Woburn, MA, USA) and the following gene-specific primers: NR3C1 $\alpha$ forward: ACCACCAGTGCCCAAAG, NR3C1 $\alpha$ reverse: TTTCATCCAGCCAACTGTG; $N R 3 C 1 \beta$ forward: CAGCGGTTTTATCAACTGAC, NR3C1 $\beta$ reverse: TGTGAGATGTGCTTTCTGG; HSD11B1 forward: AGCATTGTTGTCGTCTCCTC, HSD11B1 reverse: GAACCCATCCAAAGCAAAC; TBP forward: AAAGACCATTGCACTTCGTG, TBP reverse: GGTTCGTGGCTCTCTTATCC). All primers were synthesised by Metabion (Martinsried, Germany). The reactions contained 5-carboxy-x-rhodamine as a passive reference dye and cDNA equivalent to $75 \mathrm{ng}$ of total RNA. The PCR was performed in triplicate using an MX3000p RT-PCR system (Stratagene). The results were analysed using the LinReg PCR analysis programme. The mRNA levels of $N R 3 C 1 \alpha, N R 3 C 1 \beta$ and HSD11B1 were normalised to the level of $T B P$, a transcription-related gene that has been shown to be a suitable reference gene (because of the lowest RNA transcription range over all tissues) and has been used in many studies $(25,26)$.

The mRNA levels of HSD11B1, NR3C1 $\alpha, N R 3 C 1 \beta$ and TBP were expressed in arbitrary units (AU) as an output of LinReg programme.

\section{Statistical analyses}

All values were expressed as the mean \pm s.D., and statistical significance was set at $P<0.05$. The normality of variables was examined by Shapiro-Wilk and one-sample Kolmogorov-Smirnov tests. Mean values were compared among the groups by one-way ANOVA and post hoc analysis using the least significant difference (LSD) test, and by independent-samples $t$-test or Mann-Whitney $U$ test for variables 
Table 1 Baseline characteristics of patients. Data presented as number of cases $(n)$ or as mean \pm s.D.

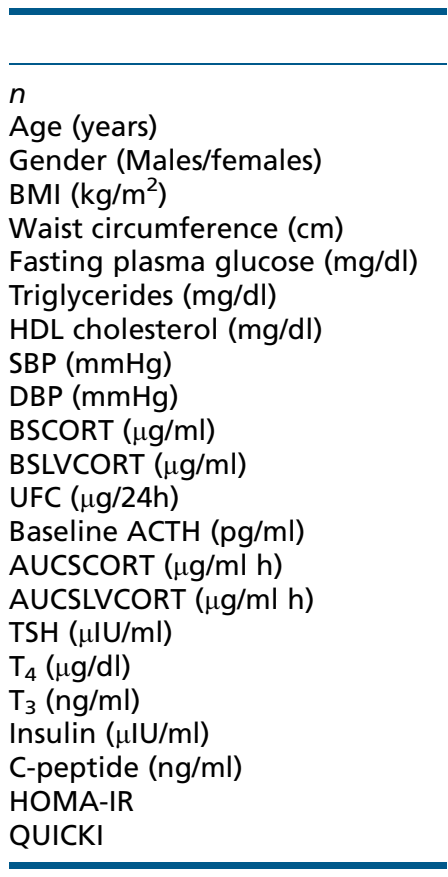

\begin{tabular}{c}
\hline Total \\
\hline 37 \\
$39.5 \pm 10$ \\
$14 / 23$ \\
$53 \pm 6.7$ \\
$142.7 \pm 15.7$ \\
$114.5 \pm 41.1$ \\
$147.5 \pm 100.1$ \\
$44 \pm 8.1$ \\
$125.7 \pm 14,9$ \\
$80.1 \pm 7.1$ \\
$13.74 \pm 6.55$ \\
$0.67 \pm 0.38$ \\
$95.46 \pm 90.4$ \\
$35.98 \pm 30$ \\
$159.18 \pm 56.14$ \\
$7.83 \pm 3.73$ \\
$2.5 \pm 1.69$ \\
$11.77 \pm 14.53$ \\
$3.94 \pm 15.73$ \\
$27.82 \pm 18.34$ \\
$5.75 \pm 5.4$ \\
$7.516 \pm 5.508$ \\
$0.298 \pm 0.026$ \\
\hline
\end{tabular}

\begin{tabular}{c} 
MetS + \\
\hline 19 \\
$44.1 \pm 9.6$ \\
$9 / 10$ \\
$52.4 \pm 5.8$ \\
$146.1 \pm 17.5$ \\
$129,8 \pm 52,6$ \\
$195.1 \pm 118.9$ \\
$41.5 \pm 6.8$ \\
$133,7 \pm 14,2$ \\
$83,2 \pm 6,5$ \\
$16.6 \pm 7.2$ \\
$0.87 \pm 0.4$ \\
$116.8 \pm 106.6$ \\
$33.04 \pm 17.61$ \\
$177.5 \pm 61.5$ \\
$9.26 \pm 4.03$ \\
$1.93 \pm 1.75$ \\
$9.90 \pm 2.03$ \\
$1.28 \pm 0.33$ \\
$31.73 \pm 22.12$ \\
$7.1 \pm 7.24$ \\
$7.902 \pm 5.72$ \\
$0.294 \pm 0.025$ \\
\hline
\end{tabular}

\begin{tabular}{c}
\hline Mets - \\
\hline 18 \\
$34.7 \pm 8.3$ \\
$5 / 13$ \\
$53.7 \pm 7.7$ \\
$139.2 \pm 13.2$ \\
$98,2 \pm 10$ \\
$97.3 \pm 32$ \\
$46.7 \pm 8.7$ \\
$117,2 \pm 10,5$ \\
$76,9 \pm 6,5$ \\
$10.7 \pm 4.1$ \\
$0.46 \pm 0.21$ \\
$71.3 \pm 62.7$ \\
$39.08 \pm 39.47$ \\
$139.8 \pm 43.5$ \\
$6.32 \pm 2.75$ \\
$3.1 \pm 1.43$ \\
$13.75 \pm 20.85$ \\
$6.74 \pm 22.53$ \\
$23.7 \pm 12.61$ \\
$4.33 \pm 1.42$ \\
$7.108 \pm 5.41$ \\
$0.302 \pm 0.028$
\end{tabular}

\begin{tabular}{cc}
\hline $\boldsymbol{P}$ \\
\hline \\
$<0.01$ \\
$\mathrm{NS}$ \\
$\mathrm{NS}$ \\
$\mathrm{NS}$ \\
$<0.01$ \\
$<0.01$ \\
$<0.05$ \\
$<0.01$ \\
$<0.01$ \\
$<0.01$ \\
$<0.01$ \\
$<0.05$ \\
$\mathrm{NS}$ \\
$<0.05$ \\
$<0.05$ \\
$<0.05$ \\
$\mathrm{NS}$ \\
$<0.01$ \\
$\mathrm{NS}$ \\
$\mathrm{NS}$ \\
$\mathrm{NS}$ \\
$\mathrm{NS}$
\end{tabular}

MetS, metabolic syndrome as defined by IDF criteria; MetS +, severely obese patients with MetS; Mets-, severely obese patients without MetS; SBP, systolic blood pressure; DBP, diastolic blood pressure; BSCORT, baseline serum cortisol; BSLVCORT, baseline salivary cortisol; UFC, urinary free cortisol; ACTH; adrenocorticotropic hormone; AUCSCORT, area under the curve of serum cortisol; AUCSLVCORT, area under the curve of salivary cortisol; TSH, thyroidstimulating hormone; HOMA-IR, homeostatic model assessment-insulin resistance; QUICKI, quantitative insulin sensitivity check index; NS, not significant.

without normal distribution. Correlation coefficients (Spearman) were performed to quantify associations. The data were analysed using SPSS version 21 (SPSS, Inc.). The area under the curve (AUC) was calculated for the serum and salivary cortisol profiles over a 24 -h period by the trapezoid rule.

\section{Results}

\section{Subject characteristics}

Table 1 gives the baseline clinical and biochemical characteristics of the subjects regarding the presence or absence of MetS as defined by the IDF criteria (5).

The baseline serum cortisol (BSCORT, MetS $+16.6 \pm$ $7.2 \mu \mathrm{g} / \mathrm{ml}$, MetS $-10.7 \pm 4.1 \mu \mathrm{g} / \mathrm{ml} ; P<0.01$ ), baseline salivary cortisol (BSLVCORT, MetS $+0.87 \pm 0.4 \mu \mathrm{g} / \mathrm{ml}$, MetS $-0.46 \pm 0.21 \mu \mathrm{g} / \mathrm{ml} ; P<0.01$ ) and UFC (MetS+ $116.8 \pm 106.6 \mu \mathrm{g} / 24 \mathrm{~h}, \quad$ MetS $-71.3 \pm 62.7 \mu \mathrm{g} / 24 \mathrm{~h}$; $P<0.05)$ were significantly higher in the MetS + group compared with the MetS- group. In the non-obese healthy controls, the normal values for BSCORT are $6.2-19.4 \mu \mathrm{g} / \mathrm{dl}$, for BSLVCORT $<0.69 \mu \mathrm{g} / \mathrm{dl}$ and for UFC $36-137 \mu \mathrm{g} / 24 \mathrm{~h}$. The AUC of serum cortisol (AUCSCORT, MetS + 177.5 $\pm 61.5 \mu \mathrm{g} / \mathrm{ml} \mathrm{h}$, MetS $-139.8 \pm 43.5 \mu \mathrm{g} / \mathrm{ml} \mathrm{h}$;
$P<0.05$ ) and the AUC of salivary cortisol (AUCSLVCORT, MetS + 9.26 $\pm 4.03 \mu \mathrm{g} / \mathrm{ml} \mathrm{h}$, MetS $-6.32 \pm 2.75 \mu \mathrm{g} / \mathrm{ml} \mathrm{h}$; $P<0.05)$ were also significantly higher in the MetS+ group than in MetS - group.

Serum TSH (Mann-Whitney $U$ test; MetS $+1.93 \pm$ $1.75 \mu \mathrm{IU} / \mathrm{ml}$, MetS $-3.1 \pm 1.43 \mu \mathrm{IU} / \mathrm{ml} ; P=0.01)$ and $\mathrm{T}_{3}$ (Mann-Whitney $U$ test; MetS $+1.28 \pm 0.33 \mathrm{ng} / \mathrm{ml}$, MetS$6.74 \pm 22.53 \mathrm{ng} / \mathrm{ml} ; P=0.005)$ levels were significantly lower in the MetS + group compared with MetS - group. $\mathrm{T}_{4}$ levels did not differ between groups. ACTH, insulin and C-peptide levels, as well as HOMA-IR, were similar between groups.

Correlations of the HPA axis parameters with MetS components $~$ BSCORT and BSLVCORT were positively correlated with the TG (TG-BSCORT, $r=0.433 ; P=0.007$ and TG-BSLVCORT, $r=0.316 ; P=0.057$ ), waist circumference (WCirc) (WCirc-BSCORT, $r=0.330 ; P=0.046$ and WCirc-BSLVCORT, $r=0.500 ; P=0.002)$ and the systolic blood pressure (SBP) (SBP-BSCORT, $r=0.349 ; P=0.034$ and SBP-BSLVCORT, $r=0.476 ; P=0.003$ ) (Fig. 1).

The WCirc was positively correlated with ACTH $(r=0.408 ; \quad P=0.012) \quad$ and AUCSCORT $\quad(r=0.319$; $P=0.054)$. The TG were also positively correlated with 

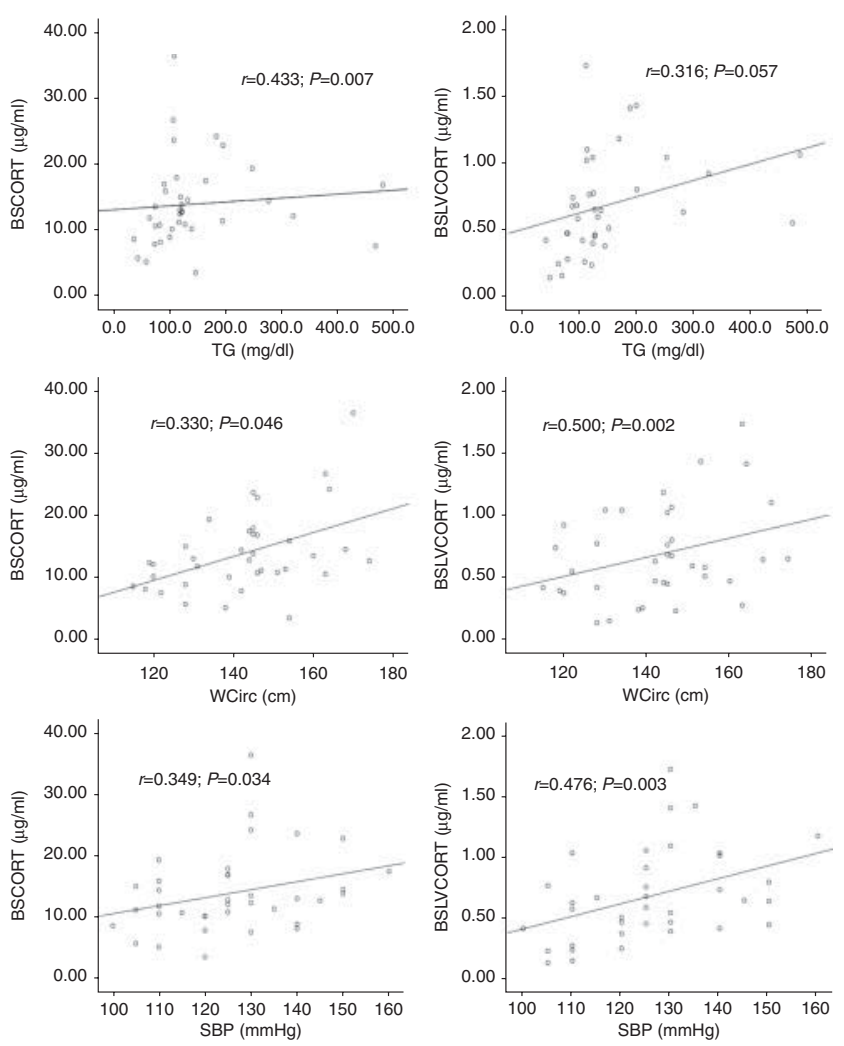

Figure 1

Correlations of BSCORT and BSLVCORT with MetS

characteristics. Bivariate correlations were established by the Spearman's $\rho$-test. BSCORT, baseline serum cortisol; BSLVCORT, baseline salivary cortisol; TG, triglycerides; SBP, systolic blood pressure.

AUCSLVCORT $(r=0.417 ; P=0.01)$. Moreover, the SBP exhibited a positive correlation with AUCSCORT $(r=$ 0.373; $P=0.023)$, AUCSLVCORT $(r=0.456 ; P=0.005)$ and UFC ( $r=0.369 ; P=0.038)$ (Fig. 2$)$.

\section{Gene expression}

The expression of the visceral HSD11B1 (VAT HSD11B1) was significantly higher in the MetS + group compared with the MetS - group (Mann-Whitney $U$ test; MetS + $0.381 \pm 0.294$ AU, MetS $-0.321 \pm 0.39$ AU; $P<0.05$ ) (Fig. 3), whereas in the SAT (Mann-Whitney $U$ test; MetS + 0.321 \pm 0.223 AU, MetS - 0.357 \pm 0.259 AU; NS) and liver (Mann-Whitney $U$ test; MetS + 6.84 $\pm 4.786 \mathrm{AU}$, MetS - 6.767 $\pm 4.642 \mathrm{AU}$; NS) there was no difference between groups. The mean HSD11B1 mRNA levels in all subjects, with or without MetS, were significantly higher in the liver $(6.804 \pm 4.651 \mathrm{AU})$ than in SAT $(0.339 \pm 0.238$
$\mathrm{AU})$ and the VAT $(0.352 \pm 0.341 \mathrm{AU})$ (one-way ANOVA, post hoc analysis by LSD test, $P<0.01$ ) (Fig. 4).

The expression of NR3C1 $\alpha$ in all of the tissue samples was similar between the two groups. The mean $N R 3 C 1 \alpha$ mRNA levels, independently of MetS designation, were significantly lower in the liver $(2.186 \pm 0.481 \mathrm{AU})$ than in SAT $(2.976 \pm 1.122 \mathrm{AU})$ and VAT $(3.234 \pm 2.381 \mathrm{AU})$ (oneway ANOVA, post hoc analysis by LSD test; $P<0.05)$ (Fig. 4). The expression of $N R 3 C 1 \beta$ was not detected either in the visceral, SAT or hepatic tissue in either group.

In the MetS - group, the expression of HSD11B1 in the liver (LHSD11B1) exhibited a negative correlation with the liver NR3C1 $\alpha(\mathrm{LNR} 3 C 1 \alpha)(r=-0.494 ; P=0.037)$ (Fig. 5), whereas no association was found in the MetS + group.
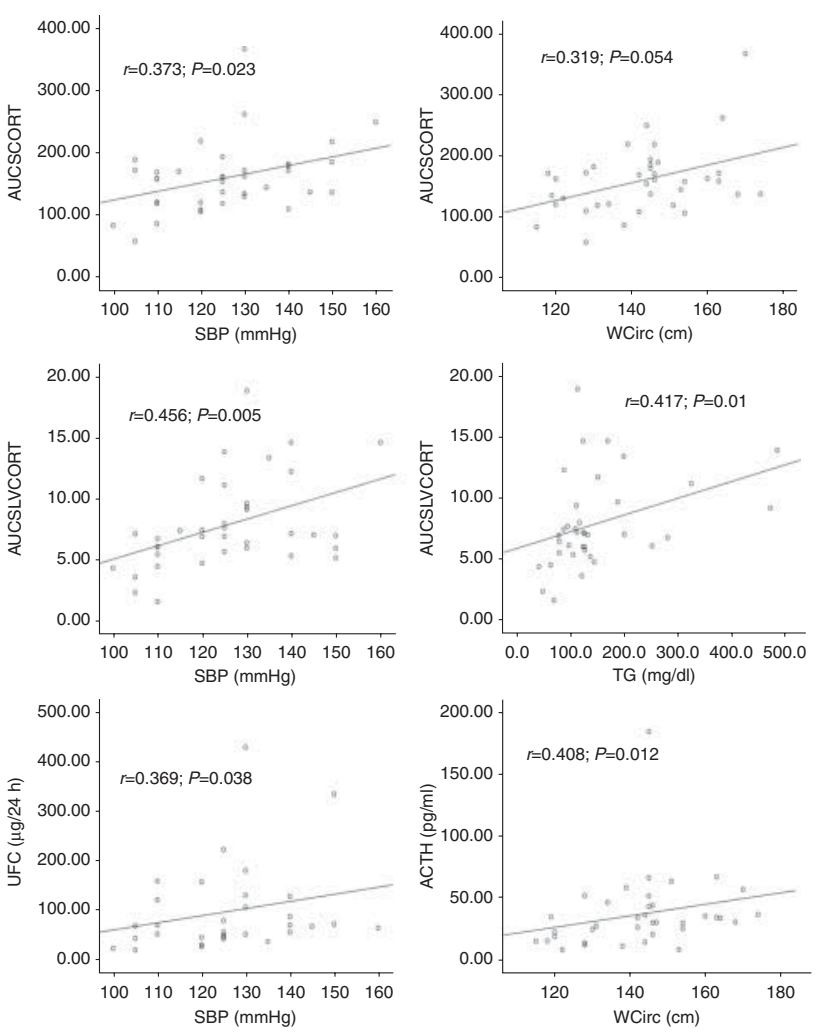

\section{Figure 2}

Correlations between hypothalamic-pituitary-adrenal (HPA) axis parameters with MetS components. Bivariate correlations were established by the Spearman's $\rho$-test. AUCSCORT, area under the curve of serum cortisol; AUCSLVCORT, area under the curve of salivary cortisol; UFC, urinary free cortisol; ACTH, adrenocorticotropic hormone; SBP, systolic blood pressure; WCirc, waist circumference; TG, triglycerides; MetS, metabolic syndrome. 


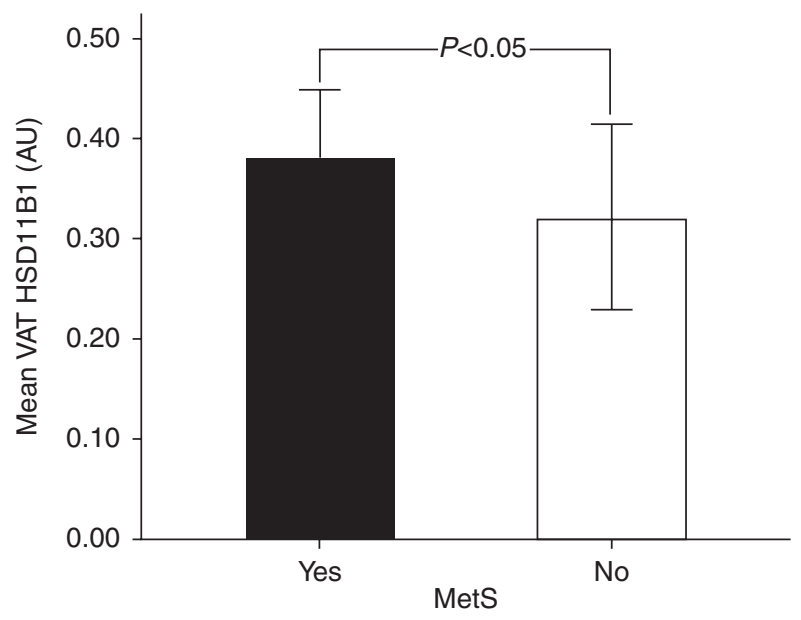

\section{Figure 3}

Mean expression of VAT HSD11B1 according to MetS. Mean values were compared among groups by independent-samples MannWhitney $U$ test. Statistical significance was set at $P<0.05$. HSD11B1, Hydroxysteroid (11-beta) dehydrogenase 1; VAT, visceral adipose tissue; MetS, metabolic syndrome; AU, arbitrary units.

Moreover, in SAT, the mRNA levels of HSD11B1 were positively correlated with $N R 3 C 1 \alpha$ expression $(r=0.505$; $P=0.033)$. In the VAT, an association between HSD11B1 and NR3C1 $\alpha$ was not detected.

\section{Correlations of HSD11B1 and NR3C1 $\alpha$ mRNA levels with MetS components}

In severely obese patients with or without MetS, visceral HSD11B1 mRNA levels (VAT HSD11B1) were positively correlated with the TG $(r=0.388 ; P=0.018)$ and WCirc ( $r=0.346$; $P=0.036$ ) (Fig. 6), both major components of MetS.

LHSD11B1 mRNA levels were positively correlated with the fasting glucose $(r=0.341 ; P=0.039)$, WCirc $(r=0.383 ; P=0.019)$ and BMI $(r=0.443 ; P=0.006)$; LNR3C1 $\alpha$ mRNA levels were inversely correlated with BMI ( $r=-0.391 ; P=0.017$ ) (Fig. 7).

\section{Other correlations}

Regardless of group (MetS + or MetS-), IR, as it was estimated by the HOMA, was positively correlated with TG $(r=0.440 ; P=0.006)$ and negatively correlated with $\mathrm{HDL}$ $(r=-0.376 ; P=0.022)$. Insulin sensitivity, as it was determined by the QUICKI, was positively correlated with HDL $(r=0.404 ; P=0.013)$, whilst exhibiting a negative correlation with TG $(r=-0.472 ; P=0.003)$ (Fig. 8).

Moreover, the TG were positively correlated with insulin $(r=0.409, P=0.012)$ and C-peptide $(r=0.500$, $P=0.002$ ) levels (Fig. 9).

\section{Discussion}

In this study, we evaluated the expression of the enzyme HSD11B1 and the NR3C1 $\alpha$, NR3C1 $\beta$ in the liver, VAT and SAT, as well as the activity of the HPA axis in severely obese patients with and without MetS.

We found that the HPA axis was activated in severely obese patients with MetS. Also, the expression of VAT HSD11B1 was higher in MetS + group, whereas in MetSgroup a negative correlation of the liver HSD11B1 mRNA levels with the LNR3C1 $\alpha$ was observed.

Independently of the MetS presence, the HSD11B1 mRNA levels were significantly higher in the liver than in SAT and VAT, a finding consistent with another study (13). This dominant expression of HSD11B1 in the liver may serve the important role of glucocorticoids in the regulation of gluconeogenic enzymes, hepatic glucose production and glycogen stores $(27,28)$. Glucocorticoids, through classical glucocorticoid-induced promoters, stimulate the transcription of crucial hepatic gluconeogenic enzymes, particularly of phosphoenolpyruvate carboxykinase and glucose 6-phosphatase (G6Pase)
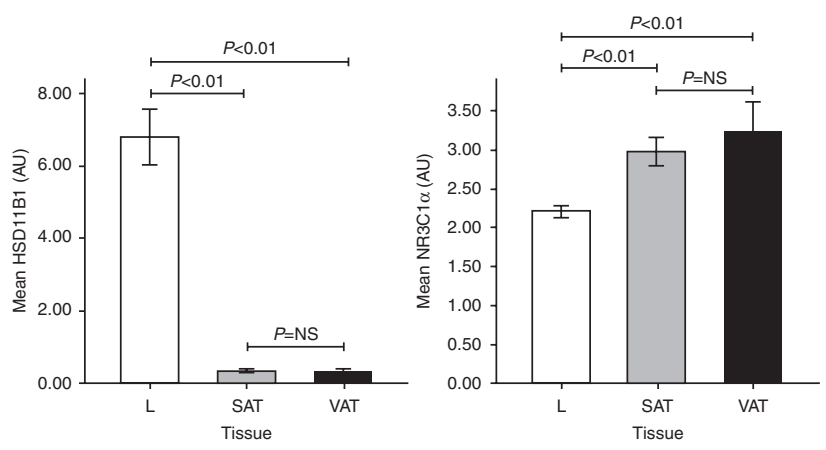

\section{Figure 4}

Mean HSD11B1 and NR3C1 $\alpha$ expression in analysed tissues. To compare tissue gene expression in liver, SAT and VAT, we used one-way ANOVA, post hoc analysis by LSD. Error bars represent \pm s.E.M. HSD11B1, Hydroxysteroid (11-beta) dehydrogenase 1; NR3C1 $\alpha$, nuclear receptor subfamily 3 , group $C$, member 1 (glucocorticoid receptor) $\alpha$; L, liver; SAT, subcutaneous adipose tissue; VAT, visceral adipose tissue; NS, not significant; $A U$, arbitrary units. 


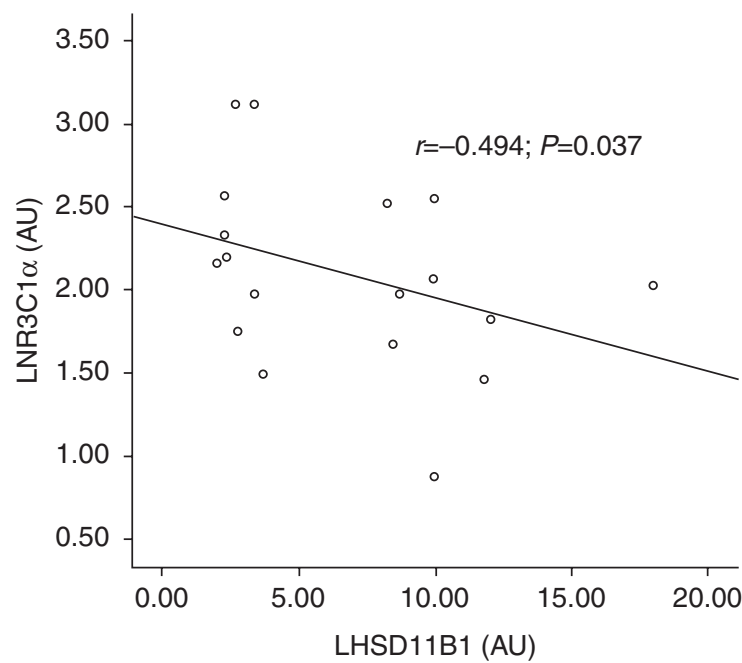

\section{Figure 5}

Correlation of LNR3C1 $\alpha$ with LHSD11B1 in MetS - group. Bivariate correlation was established by the Spearman's $\rho$-test. Statistical significance was set at $P<0.05$. LHSD11B1, liver hydroxysteroid (11-beta) dehydrogenase 1; LNR3C1 $\alpha$, liver nuclear receptor subfamily 3, group $C$, member 1 (glucocorticoid receptor) $\alpha$; MetS, metabolic syndrome; $\mathrm{AU}$, arbitrary units.

$(29,30)$. Thus, as was expected, in this study, LHSD11B1 was found to be positively correlated with fasting glucose. G6Pase also shares its substrate (glucose-6-phosphate) with hexose-6-phosphate-dehydrogenase (H6PDH). $\mathrm{H} 6 \mathrm{PDH}$ is an endoplasmic reticulum enzyme that generates cofactor NADPH and thus ameliorates NADPHdependent HSD11B1 reductase activity $(31,32,33)$. The significance of $\mathrm{H6PDH}$ was demonstrated in a study in which transgenic mice that were overexpressing H6PDH in the adipose tissue exhibited fasting hyperglycaemia, glucose intolerance with IR and elevated circulating free fatty acids (FFA) levels (34). Moreover, hepatic HSD11B1 mRNA levels were positively associated with the WCirc and BMI, suggesting that visceral obesity could induce an increase in the expression of LHSD11B1, which in turn contributes to the appearance of MetS, as is demonstrated in several animal studies (14). However, some obese subjects do not develop MetS, representing a distinguished phenotype of metabolically healthy obese subjects. Why this happens is a question we will try to answer hereinafter by suggesting some hypothetical mechanisms.

First of all, in the MetS - group the liver mRNA levels of HSD11B1 (LHSD11B1) were negatively correlated with those of NR3C1 $\alpha$ (LNR3C1 $\alpha$ ). This negative correlation could work as counter-regulatory mechanism in the appearance of MetS in severely obese patients, because cortisol exerts intracellular actions by binding to this receptor. In addition, the LNR3C $1 \alpha$ expression exhibited a negative correlation with the BMI. Taken together the downregulation of these receptors could represent a compensatory mechanism preventing the appearance of MetS in severely obese patients. In our study, the expression of $\mathrm{NR} 3 \mathrm{C} 1 \alpha$ in all tissue samples was similar between the two groups (MetS + and MetS), whereas in another study (35) it was demonstrated that the expression of NR3C1 $\alpha$ in the liver is higher in morbidly obese patients with MetS in comparison with those without. Furthermore, the mean NR3C1 $\alpha$ mRNA levels, independent of the MetS designation, were significantly lower in the liver than in the SAT and VAT. In both groups NR3C1 $\beta$ expression was not detected in any of the tissue samples.

Also, the HSD11B1 mRNA levels in the VAT (VAT HSD11B1) were significantly higher in the MetS + group when compared with the MetS- group, while there was no difference between groups in the expression of HSD11B1 in the SAT and the liver. The results are conflicting when comparing HSD11B1 mRNA levels in the adipose tissue and liver of obese patients with or without MetS. In contrast to our results, Baudrand et al. (13) did not find differences in HSD11B1 expression between obese subjects with and without MetS, while Torrecilla et al. (35) observed higher mRNA levels of HSD11B1 in the liver of patients with MetS. Nevertheless, this particular finding of ours is in line with previous studies, in animal models and more particularly in transgenic mice, where overexpression of the HSD11B1 selectively in adipose tissue led to full MetS, with visceral obesity, hypertension, dyslipidaemia and IR (14). These effects were probably induced by increased levels of FFA and cortisol delivered to the liver via the portal vein (14).
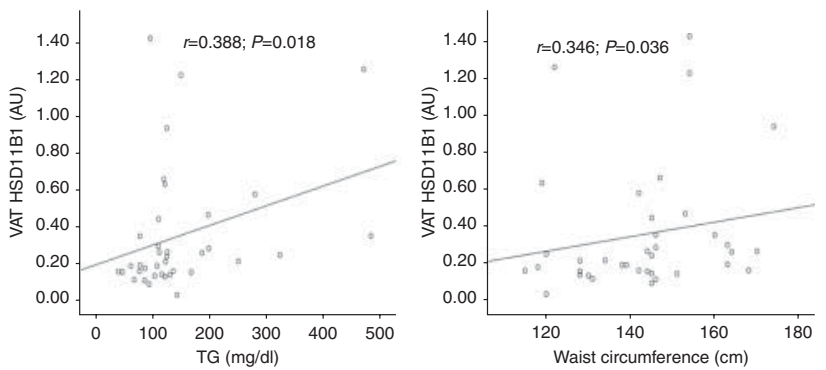

\section{Figure 6}

Correlations between VAT HSD11B1 and MetS characteristics. Bivariate correlations were established by the Spearman's $\rho$-test. VAT HSD11B1, visceral adipose tissue hydroxysteroid (11-beta) dehydrogenase 1; TG, triglycerides; AU, arbitrary units. 

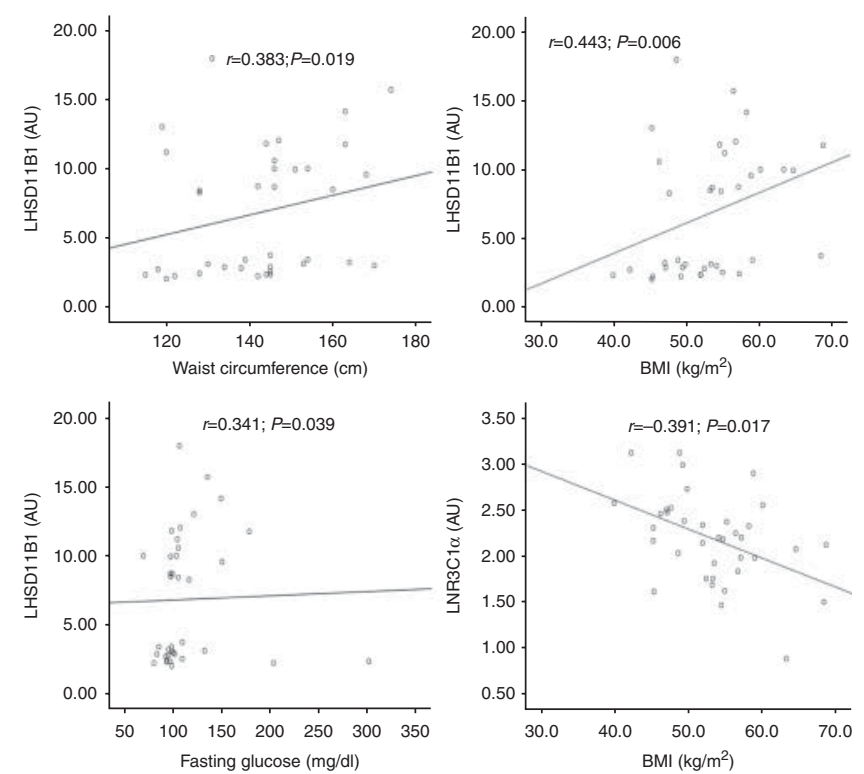

\section{Figure 7}

Correlations between mRNA levels of HSD11B1 and NR3C1 $\alpha$ in liver and MetS characteristics. Bivariate correlations were established by the Spearman's $\rho$-test. LHSD11B1, liver hydroxysteroid (11-beta) dehydrogenase 1; LNR3C1 $\alpha$, liver nuclear receptor subfamily 3, group $C$, member 1 (glucocorticoid receptor) $\alpha$; MetS, metabolic syndrome; $\mathrm{AU}$, arbitrary units.

The overexpression of HSD11B1 in the VAT leads to the overproduction of cortisol locally, which in turn increases the levels of FFA because it is known that glucocorticoids enhance lipolysis by upregulating the expression of the lipoprotein lipase (36) and the hormone-sensitive lipase (37). Considerable evidence from other studies (38) suggests that in patients with MetS, increased FFA draining from the VAT into the portal circulation contributes to hepatic IR. In addition, FFAs accelerate gluconeogenesis by providing a continuous source of energy (ATP) and substrate (39). Moreover, FFA are also known to cause systematic IR by inhibiting insulin-stimulated glucose uptake and glycogen synthesis, mainly on the site of skeletal muscles (40). Thus as was expected, in this study we found that IR, estimated by the HOMA-IR, was positively correlated with TG. We also found that VAT HSD11B1 was positively correlated with the TG levels and WCirc, both strong components of MetS. Therefore, according to our findings, we can speculate that VAT HSD11B1 overexpression is associated with the appearance of MetS in severely obese patients.

The baseline serum, salivary cortisol and UFC were significantly higher in the MetS + group compared with the MetS - group. Also, AUC of serum cortisol and AUC of salivary cortisol were significantly higher in the MetS+ group than in the MetS - group. These findings are in accordance with numerous of other studies (41, 42, 43, $44,45)$. As can be seen in Cushing's syndrome, glucocorticoid excess can cause visceral obesity, IR, diabetes mellitus, dyslipidaemia, hypertension and premature vascular mortality. We also found a strong correlation between the ACTH and baseline serum cortisol with the components of MetS, such as the WCirc, TG and SBP. This observation confirms the fact that there is an over activity of the HPA axis in patients with MetS as demonstrated in our previous study (45) and other studies (42).

A limitation of our study was that the MetS + patients were $\sim 10$ years older than the patients without MetS. We cannot exclude the possibility that some of the MetSpatients could become MetS+ due to ageing or behavioural and environmental influences during the following years. However, in our study, we did not find any correlation between age and the studied parameters. Also, in other studies $(46,47)$, no correlation was found between human tissue HSD11B1 expression and age. Moreover, it is known that the hyperactivity of the HPA axis is reported mainly in the elderly people and there are no significant differences during adulthood $(48,49)$.
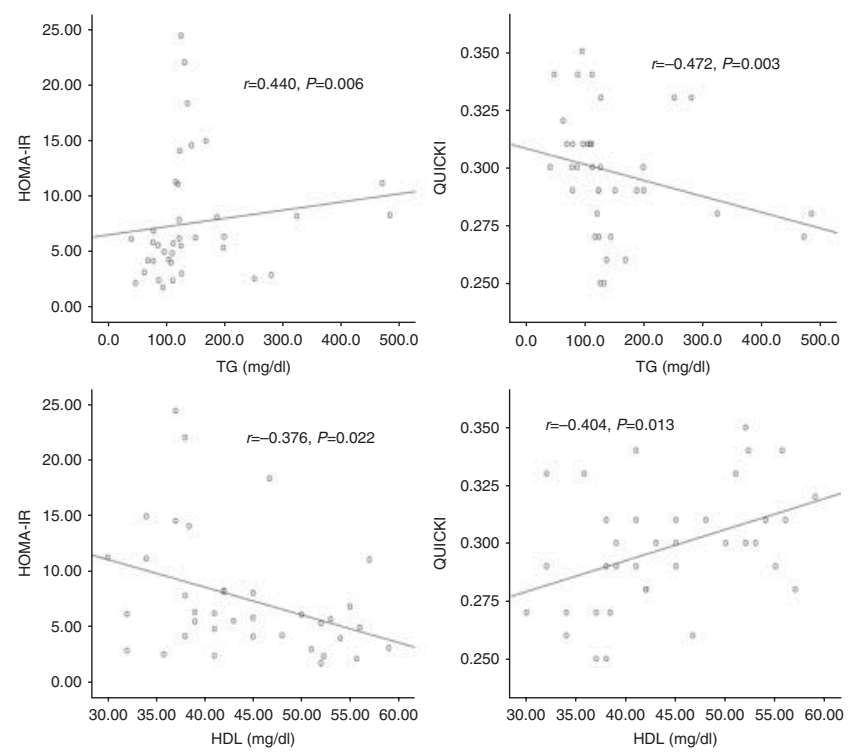

\section{Figure 8}

Correlations of HOMA-IR and QUICKI with MetS characteristics. Bivariate correlations were established by the Spearman's $\rho$-test. HOMA-IR, homeostatic model assessment-insulin resistance; QUICKI, quantitative insulin sensitivity check index; TG, triglycerides. 

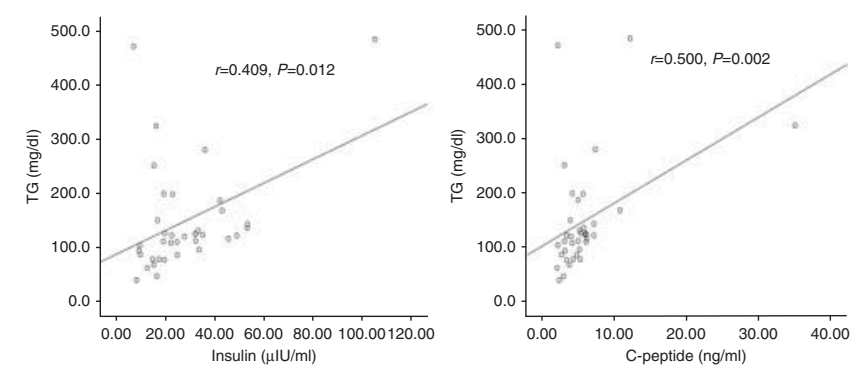

\section{Figure 9}

Correlations of TG with insulin and C-peptide. Bivariate correlations were established by the Spearman's $\rho$-test.

TG, triglycerides.

According to our findings, it seems that in severely obese patients without MetS, the downregulation of NR3C1 $\alpha$ in the liver as well as the lower expression of HSD11B1 in the VAT might protect them from the development of metabolic consequences of their obesity. Further studies are needed to investigate the exact role of cortisol production and action in tissue level, in order to clarify its contributing role in the development of MetS in severely obese patients.

\section{Declaration of interest}

The authors declare that there is no conflict of interest that could be perceived as prejudicing the impartiality of the research reported.

\section{Funding}

This research did not receive any specific grant from any funding agency in the public, commercial or not-for-profit sector.

\section{Acknowledgements}

The authors would like to thank Irene Mamali, Biologist, for the measurements of $\mathrm{ACTH}, \mathrm{TSH}, \mathrm{T}_{4}, \mathrm{~T}_{3}$, insulin, C-peptide and cortisol levels and Anna G. Antonacopoulou, Biologist, for her valuable consultation regarding the collection and preservation of the tissue samples, as well as the RNA extraction methods and PCR. A special thanks to Prof. Haralabos P Kalofonos for allowing us the use of the facilities of the Molecular Oncology Laboratory.

\section{References}

1 Reaven GM. Banding Lecture 1988. Role of insulin resistance in human disease. Diabetes 198837 1595-1607. (doi:10.2337/diab.37.12.1595)

2 Zimmet P, Alberti KG \& Shaw J. Global and societal implications of the diabetes epidemic. Nature 2001414 782-787. (doi:10.1038/414782a)

3 Alberti KG \& Zimmet PZ. Definition, diagnosis and classification of diabetes mellitus and its complications. Part 1: diagnosis and classification of diabetes mellitus provisional report of a WHO consultation. Diabetic Medicine 199815 539-553. (doi:10.1002/ (SICI)1096-9136(199807)15:7 < 539::AID-DIA668>3.0.CO;2-S)

4 Expert Panel on Detection, Evaluation, and Treatment of High Blood Cholesterol in Adults. Executive Summary of the Third Report of the National Cholesterol Education Program (NCEP) Expert Panel on Detection, Evaluation, and Treatment of High Blood Cholesterol in Adults (Adult Treatment Panel III). Journal of the American Medical Association 2001285 2486-2497. (doi:10.1001/jama.285.19.2486)

5 Alberti KG, Zimmet P \& Shaw J. Metabolic syndrome - a new worldwide definition. A consensus statement from the International Diabetes Federation. Diabetic Medicine 200623 469-480. (doi:10.1111/ j.1464-5491.2006.01858.x)

6 Peeke PM \& Chrousos GP. Hypercortisolism and obesity. Annals of the New York Academy of Sciences 1995771 665-676. (doi:10.1111/j.17496632.1995.tb44719.x)

7 Bujalska IJ, Kumar S \& Stewart PM. Does central obesity reflect "Cushing's disease of the omentum"? Lancet 1997349 1210-1213. (doi:10.1016/S0140-6736(96)11222-8)

8 Siminialayi IM \& Emem-Chioma PC. Glucocorticoids and the insulin resistance syndrome. Nigerian Journal of Medicine 200413 330-335.

9 Rabbitt EH, Lavery GG, Walker EA, Cooper MS, Stewart PM \& Hewison M. Prereceptor regulation of glucocorticoid action by $11 \beta$-hydroxysteroid dehydrogenase: a novel determinant of cell proliferation. FASEB Journal 200216 36-44. (doi:10.1096/fj.01-0582com)

10 Ricketts ML, Verhaeg JM, Bujalska I, Howie AJ, Rainey WE \& Stewart PM. Immunohistochemical localization of type $111 \beta$-hydroxysteroid dehydrogenase in human tissues. Journal of Clinical Endocrinology and Metabolism 199883 1325-1335. (doi:10.1210/jcem.83.4.4706)

11 Tomlinson JW, Walker EA, Bujalska IJ, Draper N, Lavery GG, Cooper MS, Hewison M \& Stewart PM. 11 $\beta$-hydroxysteroid dehydrogenase type 1: a tissue-specific regulator of glucocorticoid response. Endocrine Reviews 200425 831-866. (doi:10.1210/er.2003-0031)

12 Bujalska IJ, Walker EA, Tomlinson JW, Hewison M \& Stewart PM. $11 \beta$-hydroxysteroid dehydrogenase type 1 in differentiating omental human preadipocytes: from de-activation to generation of cortisol. Endocrine Research 200228 449-461. (doi:10.1081/ERC-120016822)

13 Baudrand R, Carvajal CA, Riquelme A, Morales M, Solis N, Pizarro M, Escalona A, Boza C, Pérez G, Domínguez A et al. Overexpression of $11 \beta$ hydroxysteroid dehydrogenase type 1 in hepatic and visceral adipose tissue is associated with metabolic disorders in morbidly obese patients. Obesity Surgery 201020 77-83. (doi:10.1007/s11695-009-9937-0)

14 Masuzaki H, Paterson J, Shinyama H, Morton MN, Mullins JJ, Seckl JR \& Flier JS. A transgenic model of visceral obesity and the metabolic syndrome. Science 2001294 2166-2170. (doi:10.1126/science.1066285)

15 Paterson JM, Morton NM, Fievet C, Kenyon CJ, Holmes MC, Staels B, Seckl JR \& Mullins JJ. Metabolic syndrome without obesity: hepatic overexpression of $11 \beta$-hydroxysteroid dehydrogenase type 1 in transgenic mice. PNAS 2004101 7088-7093. (doi:10.1073/pnas.0305524101)

16 Morton NM, Holmes MC, Fiévet C, Staels B, Tailleux A, Mullins JJ \& Seckl JR. Improved lipid and lipoprotein profile, hepatic insulin sensitivity, and glucose tolerance in $11 \beta$-hydroxysteroid dehydrogenase type 1 null mice. Journal of Biological Chemistry 2001 276 41293-41300. (doi:10.1074/jbc.M103676200)

17 Morton NM, Paterson JM, Masuzaki H, Holmes MC, Staels B, Fievet C, Walker BR, Flier JS, Mullins JJ \& Seckl JR. Novel adipose tissue-mediated resistance to diet-induced visceral obesity in $11 \beta$-hydroxysteroid dehydrogenase type 1-deficient mice. Diabetes 200453 931-938. (doi:10.2337/diabetes.53.4.931)

18 Kotelevtsev Y, Holmes MC, Burchell A, Houston PM, Schmoll D, Jamieson P, Best R, Brown R, Edwards CR, Seckl JR et al. 11ß-hydroxysteroid dehydrogenase type 1 knockout mice show attenuated glucocorticoid-inducible responses and resist hyperglycemia on obesity or stress. PNAS 199794 14924-14929. (doi:10.1073/pnas.94.26.14924)

19 Kim LJ, Nalls MA, Eiriksdottir G, Sigurdsson S, Launer LJ, Koster A, Chaves PH, Jonsdottir B, Garcia M, Gudnason V et al. Associations of visceral and liver fat with the metabolic syndrome across the spectrum 
of obesity: the AGES-Reykjavik study. Obesity 201119 1265-1271. (doi:10.1038/oby.2010.291)

20 Després JP, Allard C, Tremblay A, Talbot J \& Bouchard C. Evidence for a regional component of body fatness in the association with serum lipids in men and women. Metabolism 198534 967-973. (doi:10.1016/ 0026-0495(85)90147-7)

21 Després JP, Moorjani S, Tremblay A, Ferland M, Lupien PJ, Nadeau A \& Bouchard C. Relation of high plasma triglyceride levels associated with obesity and regional adipose tissue distribution to plasma lipoproteinlipid composition in premenopausal women. Clinical and Investigative Medicine 198912 374-380.

22 Gillum RF. The association of body fat distribution with hypertension, hypertensive heart disease, coronary heart disease, diabetes and cardiovascular risk factors in men and women aged 18-79 years. Journal of Chronic Diseases 198740 421-428. (doi:10.1016/0021-9681(87)90175-5)

23 Durward CM, Hartman TJ \& Nickols-Richardson SM. All-cause mortality risk of metabolically healthy obese individuals in NHANES III. Journal of Obesity 20122012 460321. (doi:10.1155/2012/460321)

24 Ortega FB, Lee DC, Katzmarzyk PT, Ruiz JR, Sui X, Church TS \& Blair SN. The intriguing metabolically healthy but obese phenotype: cardiovascular prognosis and role of fitness. European Heart Journal 201334 389-397. (doi:10.1093/eurheartj/ehs174)

25 Kannisto K, Pietilainen KH, Ehrenborg E, Rissanen A, Kaprio J, Hamsten A \& Yki-Jarvinen H. Overexpression of $11 \beta$-hydroxysteroid dehydrogenase- 1 in adipose tissue is associated with acquired obesity and features of insulin resistance: studies in young adult monozygotic twins. Journal of Clinical Endocrinology and Metabolism 200489 4414-4421. (doi:10.1210/jc.2004-0153)

26 Radonić A, Thulke S, Mackay IM, Landt O, Siegert W \& Nitsche A. Guideline to reference gene selection for quantitative real-time PCR. Biochemical and Biophysical Research Communications 2004313 856-862. (doi:10.1016/j.bbrc.2003.11.177)

27 Altuna ME, Lelli SM, San Martín de Viale LC \& Damasco MC. Effect of stress on hepatic $11 \beta$-hydroxysteroid dehydrogenase activity and its influence on carbohydrate metabolism. Canadian Journal of Physiology and Pharmacology 200684 977-984. (doi:10.1139/y06-046)

28 Holmes MC, Kotelevtsev Y, Mullins JJ \& Seckl JR. Phenotypic analysis of mice bearing targeted deletions of $11 \beta$-hydroxysteroid dehydrogenases 1 and 2 genes. Molecular and Cellular Endocrinology 2001171 15-20. (doi:10.1016/S0303-7207(00)00386-5)

29 Imai E, Stromstedt PE, Quinn PG, Carlstedt-Duke J, Gustafsson JA \& Granner DK. Characterization of a complex glucocorticoid response unit in the phosphoenolpyruvate carboxykinase gene. Molecular and Cellular Biology 199010 4712-4719. (doi:10.1128/MCB.10.9.4712)

30 Lange AJ, Argaud D, Elmaghrabi MR, Pan W, Maitra SR \& Pilkis SJ. Isolation of a cDNA for the catalytic subunit of rat liver glucose-6phosphatase: regulation of gene expression in FAO hepatoma cells by insulin, dexamethasone and cAMP. Biochemical and Biophysical Research Communications 1994201 302-309. (doi:10.1006/bbrc.1994.1702)

31 Atanasov AG, Nashev LG, Schweizer RA, Frick C \& Odermatt A. Hexose6-phosphate dehydrogenase determines the reaction direction of $11 \beta$ hydroxysteroid dehydrogenase type 1 as an oxoreductase. FEBS Letters 2004571 129-133. (doi:10.1016/j.febslet.2004.06.065)

32 Banhegyi G, Benedetti A, Fulceri R \& Senesi S. Cooperativity between 11ßhydroxysteroid dehydrogenase type 1 and hexose-6-phosphate dehydrogenase in the lumen of the endoplasmic reticulum. Journal of Biological Chemistry 2004279 27017-27021. (doi:10.1074/jbc.M404159200)

33 McCormick KL, Wang X \& Mick GJ. Evidence that the 11ßhydroxysteroid dehydrogenase (11ß-HSD1) is regulated by pentose pathway flux. Studies in rat adipocytes and microsomes. Journal of Biological Chemistry 2006281 341-347. (doi:10.1074/jbc.M506026200)

34 Wang Y, Liu L, Du H, Nagaoka Y, Fan W, Lutfy K, Friedman TC, Jiang M $\&$ Liu Y. Transgenic overexpression of hexose-6-phosphate dehydrogenase in adipose tissue causes local glucocorticoid amplification and lipolysis in male mice. American Journal of Physiology. Endocrinology and Metabolism 2014306 E543-E551. (doi:10.1152/ajpendo.00491.2013)

35 Torrecilla E, Fernández-Vázquez G, Vicent D, Sánchez-Franco F, Barabash A, Cabrerizo L, Sánchez-Pernaute A, Torres AJ \& Rubio MA. Liver upregulation of genes involved in cortisol production and action is associated with metabolic syndrome in morbidly obese patients. Obesity Surgery 201222 478-486. (doi:10.1007/s11695-011-0524-9)

36 Yang S, Xu X \& Bjorntorp P. Effects of dexamethasone on primarily cultured newly differentiated rat adipocytes from different adipose tissue regions. Obesity Research 19931 99-105. (doi:10.1002/j.15508528.1993.tb00598.x)

37 Slavin BG, Ong JM \& Kern PA. Hormonal regulation of hormone sensitive lipase activity and mRNA levels in isolated rat adipocytes. Journal of Lipid Research 199435 1535-1541.

38 Montague CT \& O'Rahilly S. The perils of portliness: causes and consequences of visceral adiposity. Diabetes 200049 883. (doi:10.2337/ diabetes.49.6.883)

39 Boden G. Role of fatty acids in the pathogenesis of insulin resistance and NIDDM. Diabetes 199545 3-10. (doi:10.2337/diab.46.1.3)

40 Boden G. Effects of free fatty acids (FFA) on glucose metabolism: significance for insulin resistance and type 2 diabetes. Experimental and Clinical Endocrinology \& Diabetes 2003111 121-124. (doi:10.1055/s-2003-39781)

41 Anagnostis P, Athyros VG, Tziomalos K, Karagiannis A \& Mikhailidis DP. Clinical review: the pathogenetic role of cortisol in the metabolic syndrome: a hypothesis. Journal of Clinical Endocrinology and Metabolism 200994 2692-2701. (doi:10.1210/jc.2009-0370)

42 Walker BR. Cortisol - cause and cure for metabolic syndrome? Diabetic Medicine 200623 1281-1288. (doi:10.1111/j.1464-5491.2006.01998.x)

43 Sen Y, Aygun D, Yilmaz E \& Ayar A. Children and adolescents with obesity and the metabolic syndrome have high circulating cortisol levels. Neuro Endocrinology Letters 200829 141-145.

44 Weigensberg MJ, Toledo-Corral CM \& Goran MI. Association between the metabolic syndrome and serum cortisol in overweight Latino youth. Journal of Clinical Endocrinology and Metabolism 200893 1372-1378. (doi:10.1210/jc.2007-2309)

45 Kazakou P, Kyriazopoulou V, Michalaki M, Ierodiakonou V, Psyrogiannis A \& Habeos I. Activated hypothalamic pituitary adrenal axis in patients with metabolic syndrome. Hormone and Metabolic Research 201244 839-844. (doi:10.1055/s-0032-1311632)

46 Mariniello B, Ronconi V, Rilli S, Bernante P, Boscaro M, Mantero F \& Giacchetti G. Adipose tissue 11ß-hydroxysteroid dehydrogenase type 1 expression in obesity and Cushing's syndrome. European Journal of Endocrinology 2006155 435-441. (doi:10.1530/eje.1.02228)

47 Paulsen SK, Pedersen SB, Fisker S \& Richelsen B. 11ß-HSD type 1 expression in human adipose tissue: impact of gender, obesity, and fat localization. Obesity 200715 1954-1960. (doi:10.1038/oby.2007.233)

48 Larsson CA, Cullberg B, Rastam L \& Lindblad U. Salivary cortisol differs with age and sex and shows inverse associations with WHR in Swedish women: a cross-sectional study. BMC Endocrine Disorders 2009916. (doi:10.1186/1472-6823-9-16)

49 Ferrari E, Cravello L, Muzzoni B, Casarotti D, Paltro M, Solerte SB, Fioravanti M, Cuzzoni G, Pontiggia B \& Magri F. Age-related changes of the hypothalamic-pituitary-adrenal axis: pathophysiological correlates. European Journal of Endocrinology 2001144 319-329. (doi:10.1530/ eje.0.1440319)

Received 26 July 2014

Revised version received 30 September 2014

Accepted 20 October 2014 